\title{
Outpatient Surgery in the Cervical Spine: Is It Safe?
}

\author{
Michael J. Lee ${ }^{1}$ lain Kalfas ${ }^{2}$ Haley Holmer ${ }^{3}$ Andrea Skelly ${ }^{3}$
}

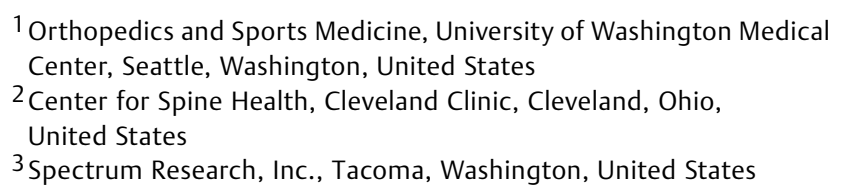

Address for correspondence Michael J. Lee, MD, Orthopedics and Sports Medicine, University of Washington Medical Center, 1959 NE Pacific Street, Box 356500, Seattle, WA 98195, United States (e-mail: Mj13000@uw.edu).

Evid Based Spine Care J 2014;5:101-111.

\begin{abstract}
Keywords

- outpatient surgery

- anterior cervical surgery

- cervical disc herniation

- cervical spondylosis

Study Design Systematic review.

Study Rationale As the length of stay after cervical spine surgery has decreased substantially, the feasibility and safety of outpatient cervical spine surgery come into question. Although minimal length of stay is a targeted metric for quality and costs for medical centers, the safety of outpatient cervical spine surgery has not been clearly defined.

Objective The objective of this article is to evaluate the safety of inpatient versus outpatient surgery in the cervical spine for adult patients with symptomatic or asymptomatic degenerative disc disease.

Methods A systematic review of the literature was undertaken for articles published through February 19, 2014. Electronic databases and the bibliographies of key articles were searched to identify comparative studies evaluating the safety of inpatient versus outpatient surgery in the cervical spine. Spinal cord stimulation, spinal injections, and diagnostic procedures were excluded. Two independent reviewers assessed the strength of evidence using the Grading of Recommendations, Assessment, Development, and Evaluation (GRADE) system, and disagreements were resolved by consensus. Results Five studies that met the inclusion criteria were identified. One study reported low risk of hematoma ( $0 \%$ of outpatients and $1.6 \%$ of inpatients). Two studies reported on mortality and both reported no deaths in either group following surgery. Dysphagia risks ranged from 0 to $10 \%$ of outpatients and 1.6 to $5 \%$ of inpatients, and infection risks ranged from 0 to $1 \%$ of outpatients and 2 to $2.8 \%$ of inpatients. One study reported that no (0) outpatients were readmitted to the hospital due to a complication, compared with four inpatients (7\%). The overall strength of evidence was insufficient for all safety outcomes examined.

Conclusion Though the studies in our systematic review did not suggest an increased risk of complication with outpatient cervical spine surgery, the strength of evidence to make a recommendation was insufficient. Further study is needed to more clearly define the role of outpatient cervical spine surgery.
\end{abstract}

(c) 2014 Georg Thieme Verlag KG Stuttgart - New York
DOI http://dx.doi.org/ 10.1055/s-0034-1389088. ISSN 1663-7976. 


\section{Study Rationale and Context}

As the length of stay after cervical spine surgery has decreased substantially, the feasibility and safety of outpatient cervical spine surgery come into question. Although minimal length of stay is a targeted metric for quality and costs for medical centers, the safety of outpatient cervical spine surgery has not been clearly defined. Because of the location of surgery, complications that may be innocuous in other parts of the body can literally be fatal in the neck. A compressive hematoma after cervical spine surgery can compromise the airway and if not addressed rapidly, can result in hypoxic complications. A patient in a home setting will not receive medical attention as quickly as an inpatient. In the context of airway compromise, this difference may be critical. This study seeks to examine the safety of outpatient cervical spine surgery.

\section{Objective}

The objective of this article is to evaluate the safety of inpatient versus outpatient surgery in the cervical spine for adult patients with symptomatic or asymptomatic degenerative disc disease.

\section{Materials and Methods}

Study design: Systematic review.

Search: PubMed, Cochrane Collaboration, EMBASE, National Guideline Clearinghouse databases; bibliographies of key articles.

Dates searched: The dates were searched through February 19, 2014.

Inclusion criteria: The inclusion criteria for the study include the following: (1) patients 18 years of age or older with symptomatic or asymptomatic degenerative disc disease (including myelopathy and radiculopathy), (2) single- or multi-level surgery in the cervical spine (including discectomy, decompression, fusion, arthroplasty), and (3) comparative studies published in peer-reviewed journals (see -Table 6 in the online supplementary material).

Exclusion criteria: The exclusion criteria for the study include the following: (1) spinal cord stimulation, spinal injections, diagnostic procedures; (2) studies with fewer than 10 subjects per treatment arm; and (3) case series. Outcomes: The outcomes of the study included the following: hematoma, death, and other adverse events.

Analysis: Descriptive statistics. Details about methods can be found in the online supplementary material.

Overall strength of evidence: Risk of bias for individual studies was based on using criteria set by the Journal of Bone and Joint Surgery ${ }^{1}$ modified to delineate criteria associated with methodological quality and risk of bias, based on recommendation from the Agency for Healthcare Research and Quality. ${ }^{2,3}$ The overall strength of evidence across studies was based on precepts outlined by the GRADE Working Group $^{4}$ and recommendations made by the Agency for Healthcare Research and Quality (AHRQ)., ${ }^{2,3}$

\section{Results}

- Five comparative studies ${ }^{5-9}$ met the inclusion criteria (-Fig. 1). All compared anterior cervical discectomy and fusion (ACDF) with allograft (one also included autograft) ${ }^{7}$ in an inpatient versus outpatient setting; two included plate fixation. ${ }^{5,7}$ Three studies included single- or multilevel surgeries, ${ }^{6-8}$ one study included single-level surgeries only, ${ }^{5}$ and one study did not report on number of surgical levels ${ }^{9}$ (- Tables $\mathbf{1}$ and 2; see also - Table 5 in the online supplementary material).

- Overall, a total of 281 outpatients and 813 inpatients were represented in the included studies, with approximately the same number of males and females ranging in age from 22 to 89 years. Detailed characteristics of the included studies are provided in - Table 1.

- All five studies were retrospective cohort studies determined to be of moderately high risk of bias (Class of Evidence [CoE] III). Further details on the CoE rating for these studies can be found in the online supplementary material in -Table $\mathbf{2 a}$.

\section{Safety Outcomes}

\section{Hematoma}

- In one study, ${ }^{5}$ hematoma occurred in zero patients in the outpatient group and in one patient (1.6\%) in the inpatient group. The other four studies did not report on risk of hematoma.

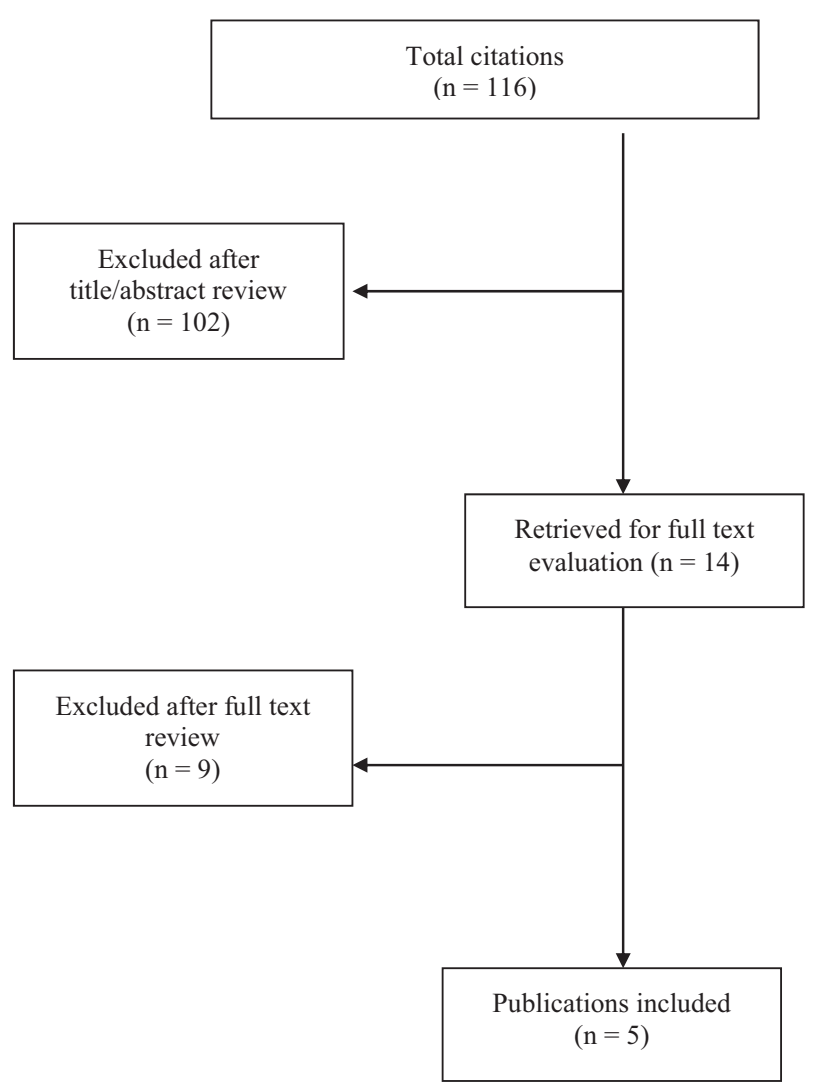

Fig. 1 Flowchart showing results of literature search. 


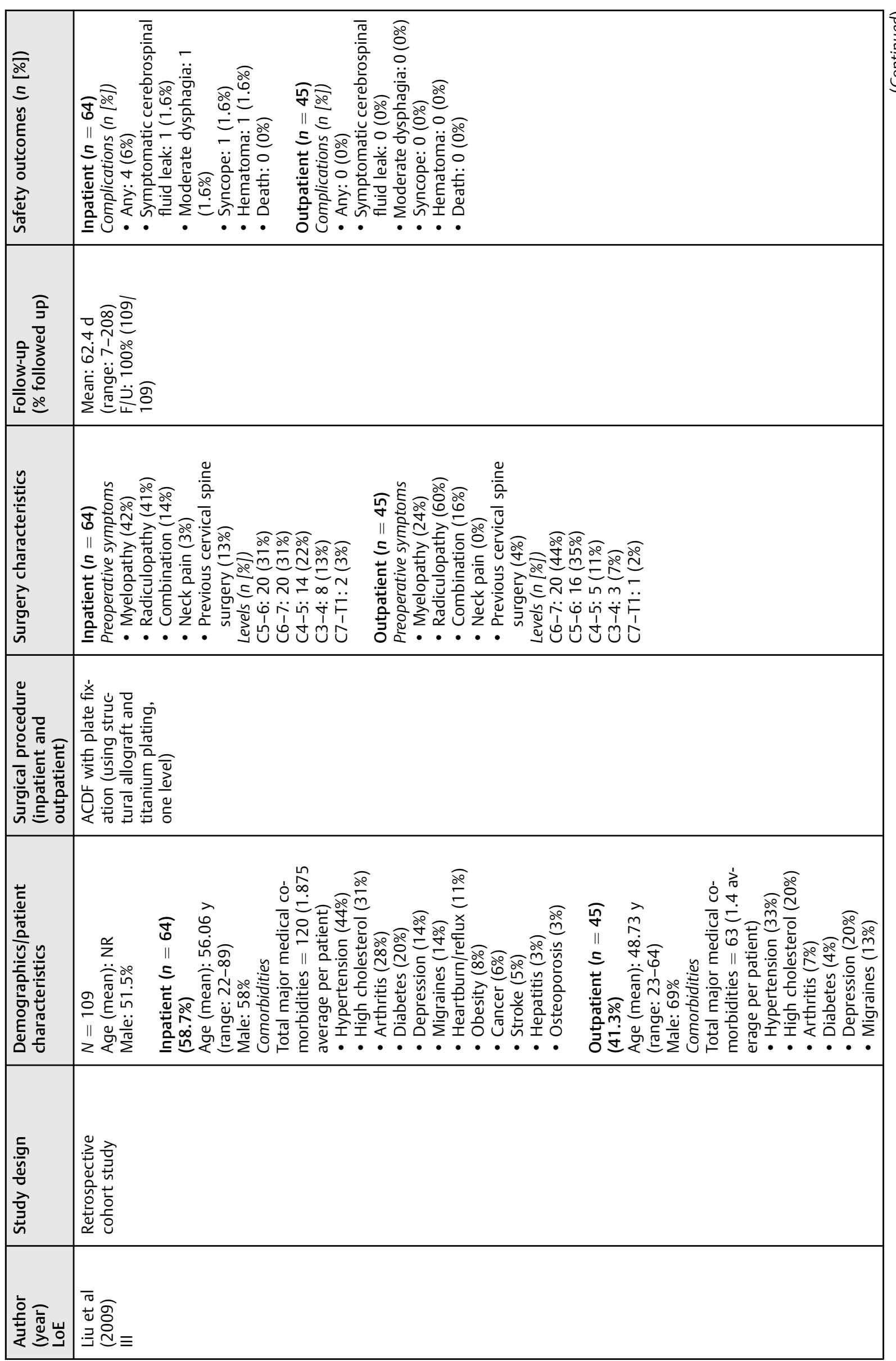




\begin{tabular}{|c|c|c|c|c|}
\hline 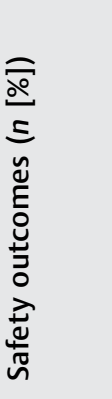 & & 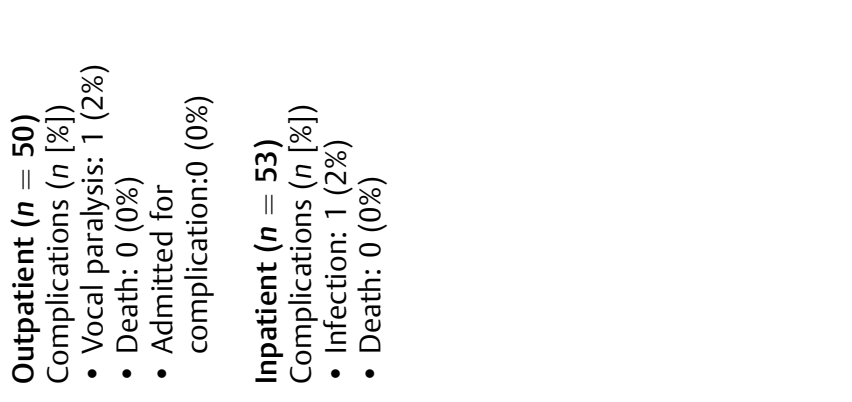 & & 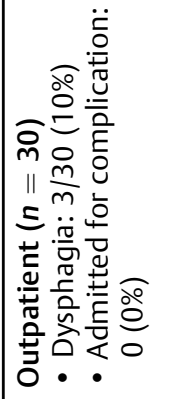 \\
\hline 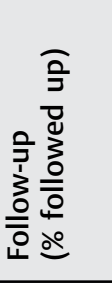 & & 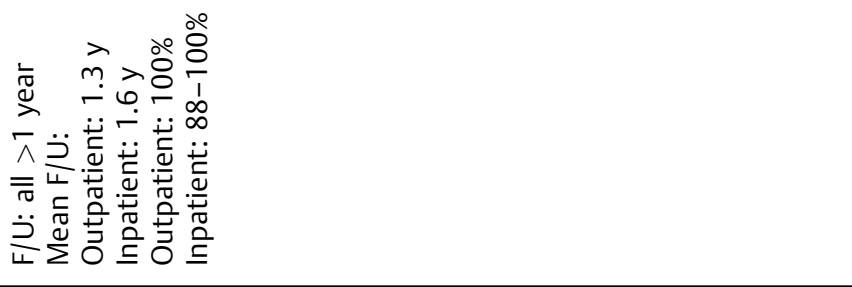 & & 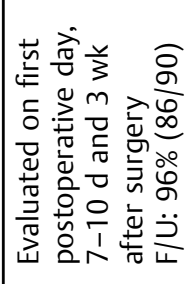 \\
\hline 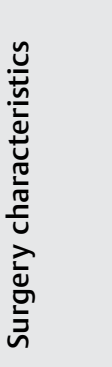 & & 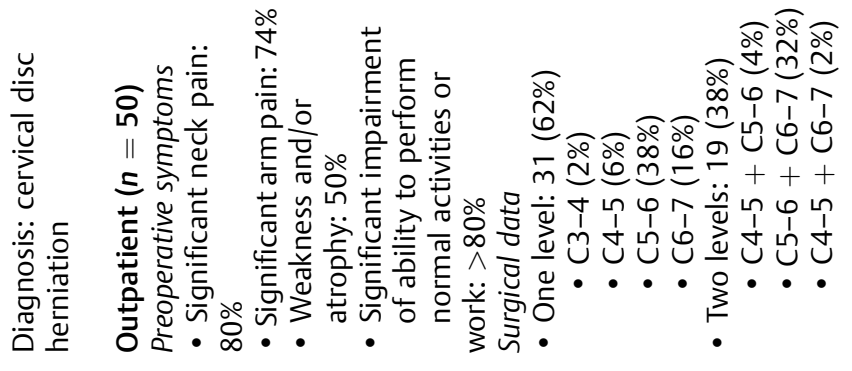 & 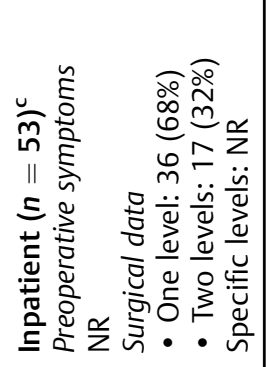 & 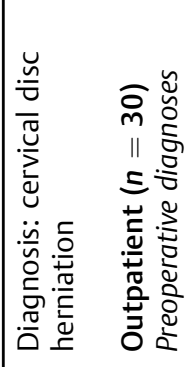 \\
\hline 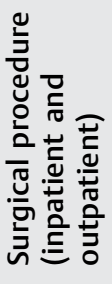 & & 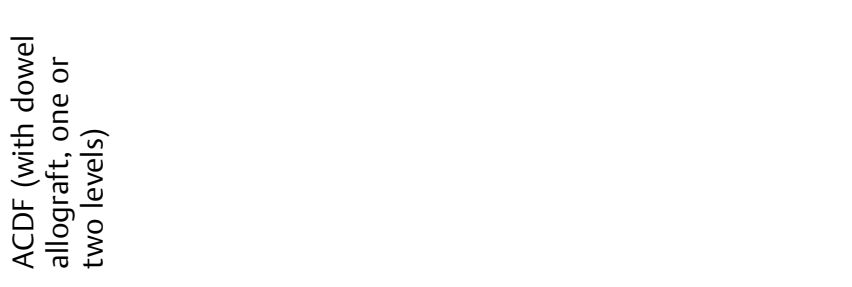 & & 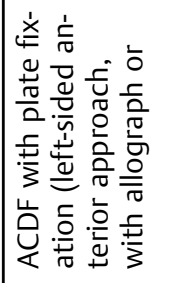 \\
\hline 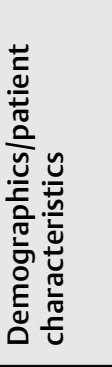 & 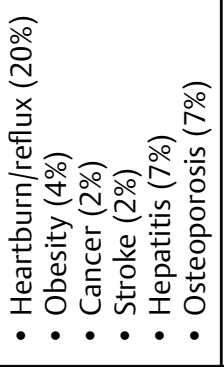 & 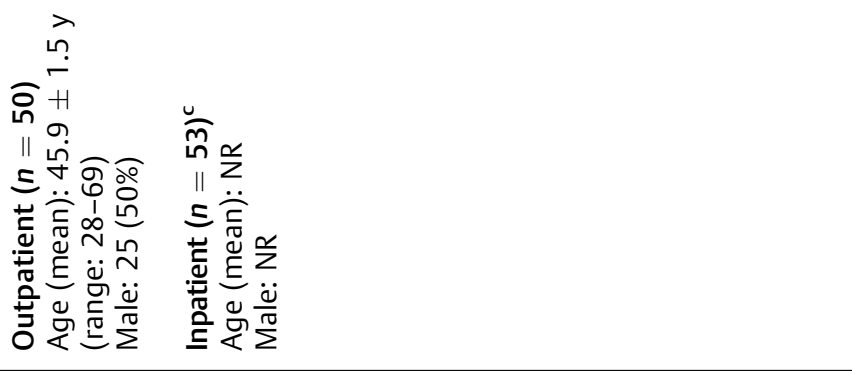 & & 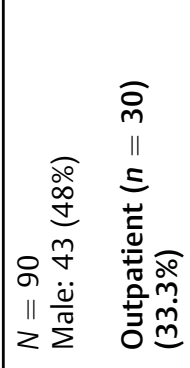 \\
\hline 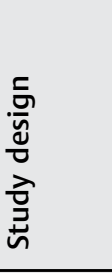 & & 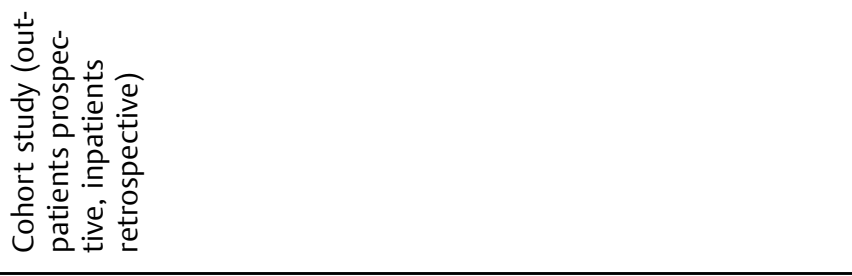 & & 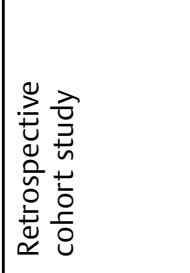 \\
\hline 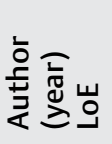 & & 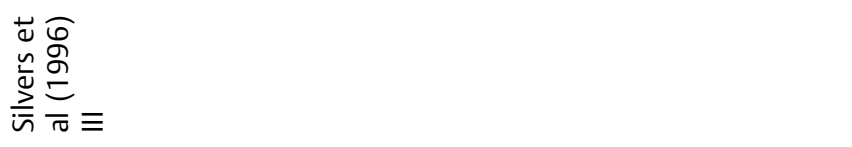 & & 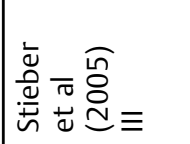 \\
\hline
\end{tabular}




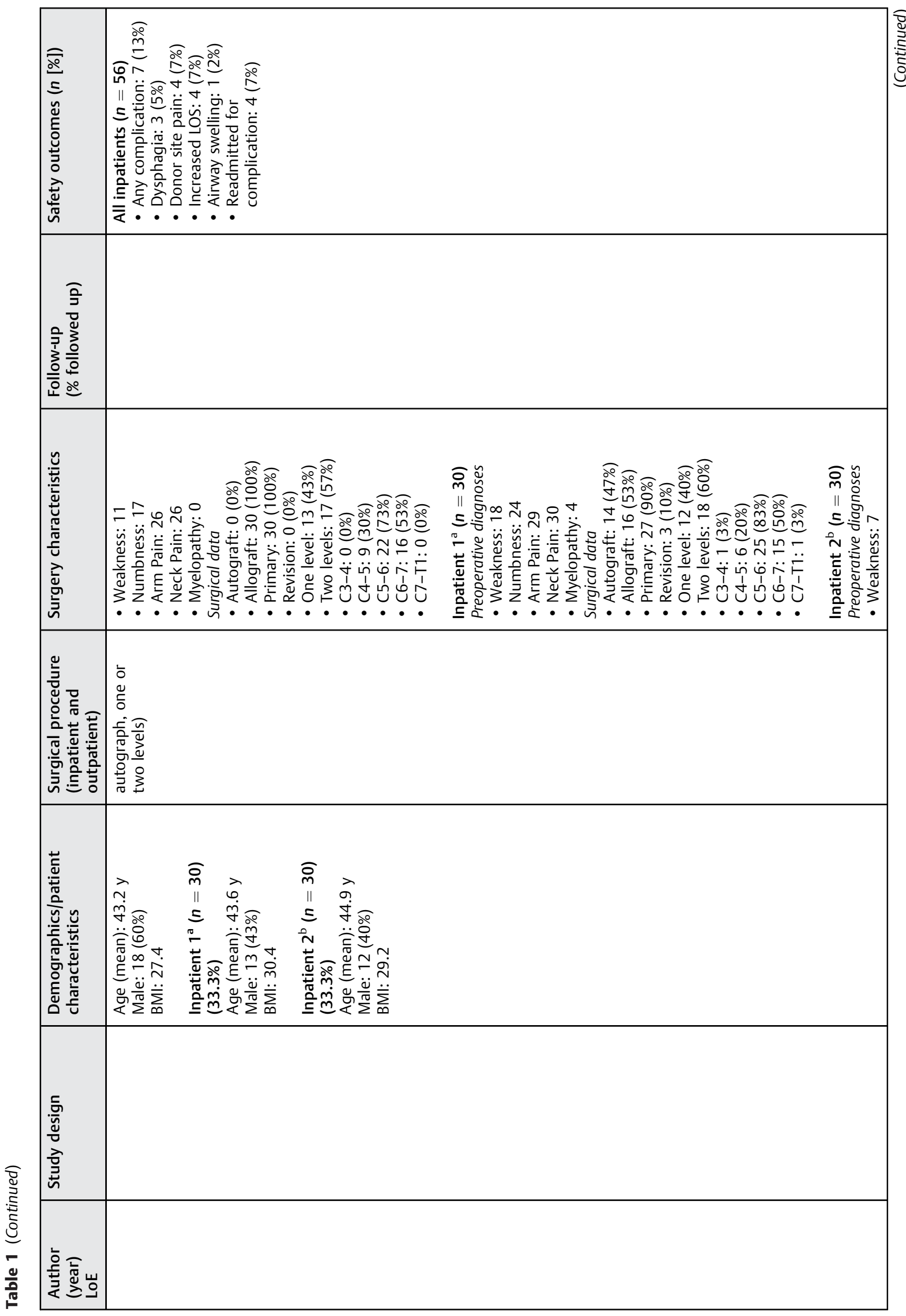




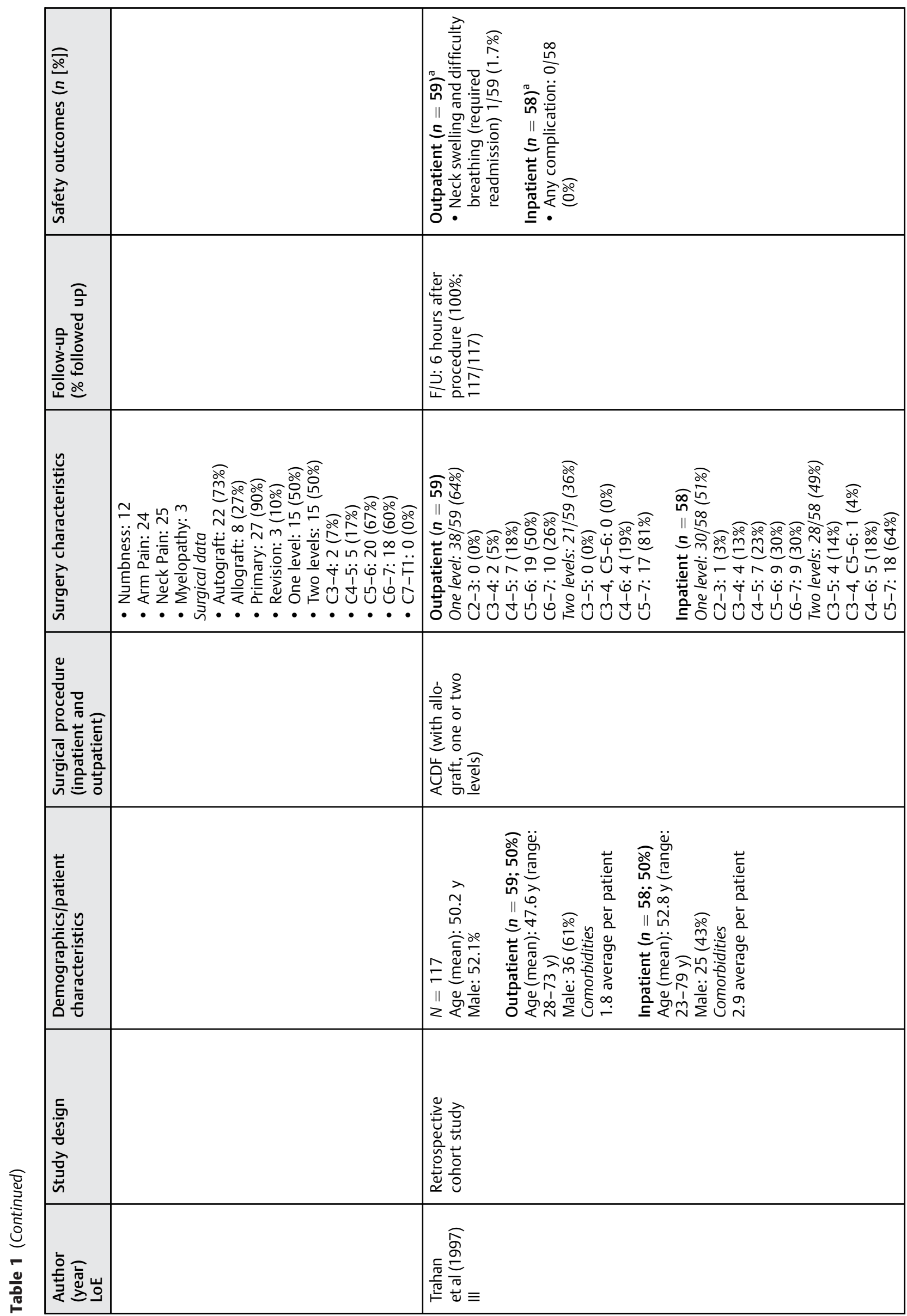



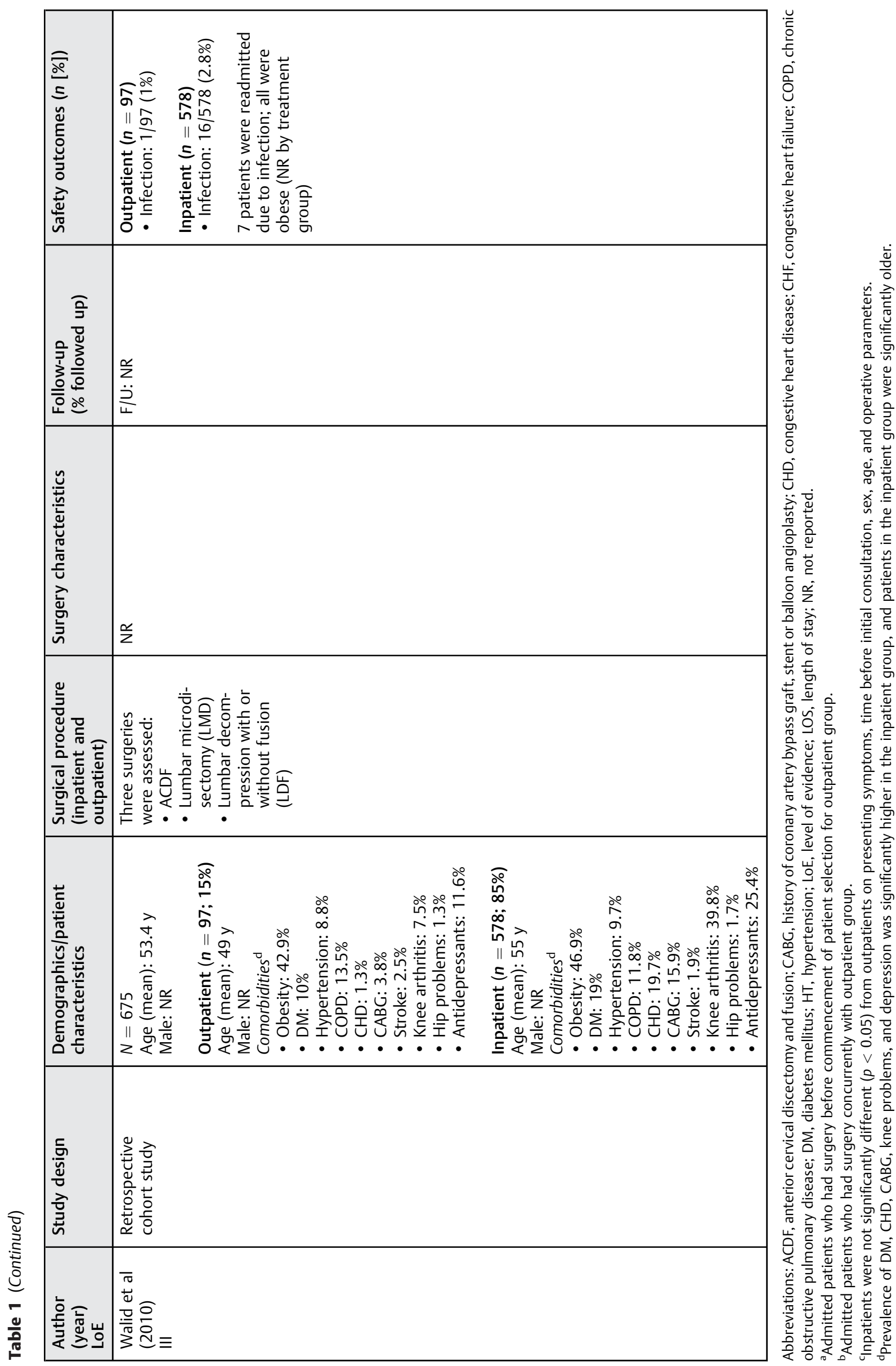
Table 2 Summary of safety outcomes in studies comparing outpatient and inpatient surgery in the cervical spine

\begin{tabular}{|c|c|c|c|c|c|}
\hline $\begin{array}{l}\text { Author (year) } \\
\text { Study design } \\
\text { LoE }\end{array}$ & Diagnosis & $\begin{array}{l}\text { Surgical } \\
\text { intervention } \\
\text { levels }\end{array}$ & $\begin{array}{l}\text { Hematoma } \\
(n[\%])\end{array}$ & $\begin{array}{l}\text { Mortality } \\
(n[\%])\end{array}$ & Other safety outcomes ( $n$ [\%]) \\
\hline $\begin{array}{l}\text { Liu et al } \\
\text { (2009) } \\
\text { Retrospective cohort } \\
\text { study } \\
\text { III }\end{array}$ & NR & $\begin{array}{l}\text { ACDF with plate } \\
\text { fixation (using struc- } \\
\text { tural allograft and } \\
\text { titanium plating) } \\
\text { One level }\end{array}$ & $\begin{array}{l}\text { Outpatient } \\
(n=45): 0 \\
(0 \%) \\
\text { Inpatient } \\
(n=64): 1 \\
(1.6 \%)\end{array}$ & $\begin{array}{l}\text { Outpatient } \\
(n=45): 0 \\
(0 \%) \\
\text { Inpatient } \\
(n=64): 0 \\
(0 \%)\end{array}$ & $\begin{array}{l}\text { Outpatient }(\boldsymbol{n}=45) \\
\text { - Any complication: } 0(0 \%) \\
\text { - Symptomatic cerebrospinal } \\
\quad \text { fluid leak: } 0(0 \%) \\
\text { - Moderate dysphagia: } 0(0 \%) \\
\text { - Syncope: } 0(0 \%) \\
\text { Inpatient }(n=64) \\
\text { - Any: } 4(6 \%) \\
\text { - Symptomatic cerebrospinal } \\
\quad \text { fluid leak: } 1(1.6) \\
\text { - Moderate dysphagia: } 1(1.6) \\
\text { - Syncope: } 1(1.6)\end{array}$ \\
\hline $\begin{array}{l}\text { Silvers et al } \\
\text { (1996) } \\
\text { Retrospective cohort } \\
\text { study } \\
\text { III }\end{array}$ & $\begin{array}{l}\text { Cervical disc } \\
\text { herniation }\end{array}$ & $\begin{array}{l}\text { ACDF (with dowel } \\
\text { allograft) } \\
\text { One or two levels }\end{array}$ & NR & $\begin{array}{l}\text { Outpatient } \\
(n=50): 0 \\
(0 \%) \\
\text { Inpatient } \\
(n=53): 0 \\
(0 \%)\end{array}$ & $\begin{array}{l}\text { Outpatient }(n=50) \\
\text { - Vocal paralysis: } 1(2 \%) \\
\text { - Admitted for complication: } \\
\quad 0(0 \%) \\
\text { - Infection } 0(0 \%) \\
\text { Inpatient }(n=53) \\
\text { - Infection: } 1(2 \%) \\
\end{array}$ \\
\hline $\begin{array}{l}\text { Stieber et al } \\
(2005) \\
\text { Retrospective cohort } \\
\text { study } \\
\text { III }\end{array}$ & $\begin{array}{l}\text { Cervical disc } \\
\text { herniation }\end{array}$ & $\begin{array}{l}\text { ACDF with plate fixa- } \\
\text { tion (left-sided ante- } \\
\text { rior approach, with } \\
\text { allograph or auto- } \\
\text { graph) } \\
\text { One or two levels }\end{array}$ & NR & NR & $\begin{array}{l}\text { Outpatient }(n=30) \\
\text { - Dysphagia: } 3(10 \%) \\
\text { - Admitted for complication: } \\
0(0 \%) \\
\text { Inpatient }(n=56) \\
\text { - Any complication: } 7(13 \%) \\
\text { - Dysphagia: } 3(5 \%) \\
\text { - Donor site pain: } 4(7 \%) \\
\text { - Increased LOS: } 4(7 \%) \\
\text { - Airway swelling: } 1(2 \%) \\
\text { - Readmitted for complication: } \\
\quad 4(7 \%)\end{array}$ \\
\hline $\begin{array}{l}\text { Trahan et al } \\
\text { (1997) } \\
\text { Retrospective cohort } \\
\text { study } \\
\text { III }\end{array}$ & NR & $\begin{array}{l}\text { ACDF (with allograft) } \\
\text { One or two levels }\end{array}$ & NR & NR & $\begin{array}{l}\text { Outpatient }(\boldsymbol{n}=59) \\
\text { - Neck swelling and difficulty } \\
\text { breathing (required readmis- } \\
\text { sion): } 1 / 59(1.7 \%) \\
\text { Inpatient }(\boldsymbol{n}=58) \\
\text { - Any complication: } 0 / 58(0 \%)\end{array}$ \\
\hline $\begin{array}{l}\text { Walid et al } \\
(2010) \\
\text { Retrospective cohort } \\
\text { study } \\
\text { III }\end{array}$ & NR & $\begin{array}{l}\text { - ACDF } \\
\text { - Lumbar microdi- } \\
\text { sectomy (LMD) } \\
\text { - Lumbar decom- } \\
\text { pression with or } \\
\text { without fusion } \\
\text { (LDF) } \\
\text { Levels: NR }\end{array}$ & NR & NR & $\begin{array}{l}\text { Outpatient }(\boldsymbol{n}=97) \\
\text { - Infection: } 1 / 97(1 \%) \\
\text { Inpatient }(\boldsymbol{n}=578) \\
\text { - Infection: } 16 / 578(2.8 \%) \\
7 \text { patients were readmitted } \\
\text { due to infection; all were obese } \\
\text { (NR by treatment group) }\end{array}$ \\
\hline
\end{tabular}

Abbreviations: ACDF, anterior cervical discectomy and fusion; CABG, history of coronary artery bypass graft, stent or balloon angioplasty; CHD, congestive heart disease; CHF, congestive heart failure; COPD, chronic obstructive pulmonary disease; DM, diabetes mellitus; HT, hypertension; LOS, length of stay; NR, not reported.

\section{Mortality}

- Two studies ${ }^{5,6}$ reported on mortality. Both studies reported zero deaths in both the inpatient and outpatient groups.

\section{Other Safety Outcomes}

- Two studies reported data on dysphagia, with one study ${ }^{7}$ reporting higher risk than the other. ${ }^{5}$ One study ${ }^{5}$ reported low risk of moderate dysphagia ( 0 and $1.6 \%$ ) in the outpatient and inpatient groups, respectively. The other ${ }^{7}$ reported higher risk, with $10 \%$ of outpatients and $5 \%$ of inpatients experiencing this complication.
- Two studies reported on postoperative infection risk. One study $^{9}$ reported that 16 patients $(2.8 \%)$ who underwent surgery as inpatients developed infection, compared with 1 patient (1\%) in the outpatient group. The other ${ }^{6}$ reported that one patient $(2 \%)$ in the inpatient group experienced infection following surgery.

- Three studies reported data on patients who needed to be readmitted following surgery due to a complication. All three studies reported data for outpatients: two studies ${ }^{6,7}$ reported that zero outpatients were readmitted and one study $^{8}$ reported that one outpatient was readmitted (due to neck swelling and difficulty breathing). One study 
Table 3 Evidence Summary

\begin{tabular}{|c|c|c|c|c|c|}
\hline Outcome & \multicolumn{4}{|c|}{ Strength of evidence } & Conclusions/comments \\
\hline Hematoma & Insufficient & Low & Moderate & High & $\begin{array}{l}\text { One small LoE III study reported hematoma in one patient } \\
(1.6 \%) \text { in the inpatient group compared to zero patients }(0 \%) \text { in } \\
\text { the outpatient group. }\end{array}$ \\
\hline Mortality & Insufficient & Low & Moderate & High & $\begin{array}{l}\text { Two small LoE III studies reported zero deaths in both the } \\
\text { inpatient and outpatient groups. }\end{array}$ \\
\hline Dysphagia & Insufficient & Low & Moderate & High & $\begin{array}{l}\text { Two small LoE II studies reported on dysphagia, ranging from } \\
0-10 \% \text { of outpatients and } 1.6-5 \% \text { of inpatients. }\end{array}$ \\
\hline Infection & Insufficient & Low & Moderate & High & $\begin{array}{l}\text { Two small LoE III studies reported similar risks of infection in } \\
\text { the inpatient group compared with the outpatient group } \\
\text { ( } 2.8 \% \text { versus } 1 \% \text { in one study and } 2 \% \text { versus } 0 \% \text { in the other, } \\
\text { respectively). }\end{array}$ \\
\hline $\begin{array}{l}\text { Other } \\
\text { complications }\end{array}$ & Insufficient & Low & Moderate & High & $\begin{array}{l}\text { All five LoE III studies reported on risks of other complications, } \\
\text { including vocal paralysis, syncope, CSF leak, and airway swelling, } \\
\text { but there was no overlap in these additional outcomes across } \\
\text { studies. The complication risks were very low in both inpatient } \\
\text { and outpatient groups, with the exception of hospital re-ad- } \\
\text { mission, which in a single study was higher in the inpatient group } \\
\text { ( } 7 \% \text { ) compared with the outpatient group ( } 0 \%) \text {. All studies had } \\
\text { small sample sizes ( } 50 \text { patients per treatment group), except } \\
\text { one study of } 97 \text { outpatients and } 578 \text { inpatients. }\end{array}$ \\
\hline
\end{tabular}

Abbreviations: CSF, cerebral spinal leak; LoE, level of evidence.

reported data for inpatients and found that four patients (7\%) were readmitted for a complication. ${ }^{7}$

- Data on additional safety outcomes are provided in -Table 2, and a summary of the strength of evidence is provided in - Table 3 (additional details on the strength of evidence are located in - Table 4 of the online supplementary material).

\section{Clinical Guidelines}

None found.

\section{Evidence Summary}

The overall strength of evidence for safety of outpatient surgery in the cervical spine is insufficient for all outcomes examined, that is, the limited evidence available prevents any definitive conclusions. There are few studies that have been done, and they are of poor quality, indicating a need for further well-designed, prospective studies (-Table 3). Details on the methodology for determining the strength of evidence, criteria used for upgrading

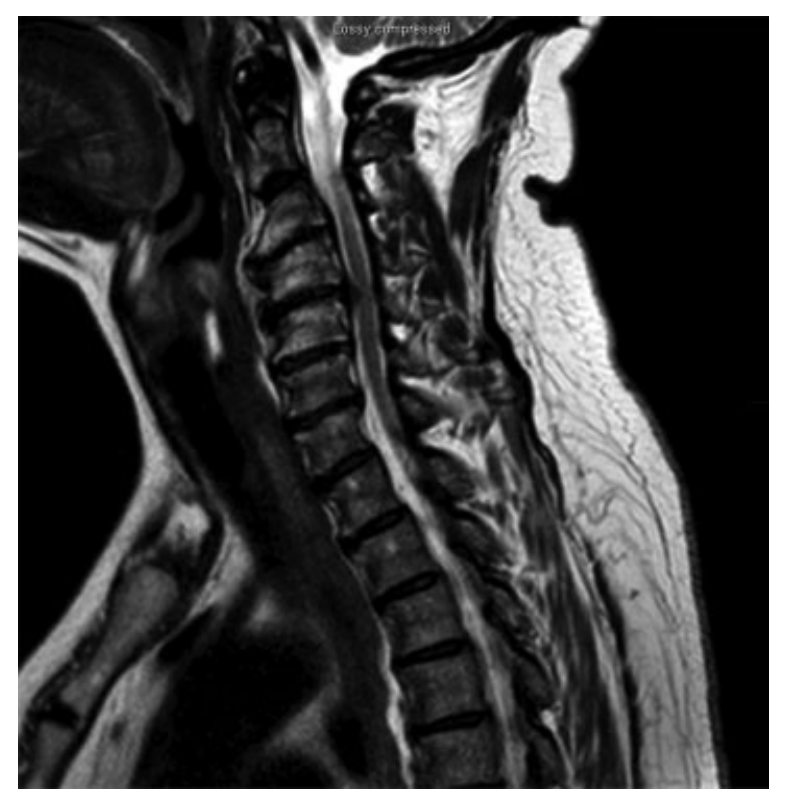

Fig. 2 T2 sagittal view of severe C4-5 stenosis. 


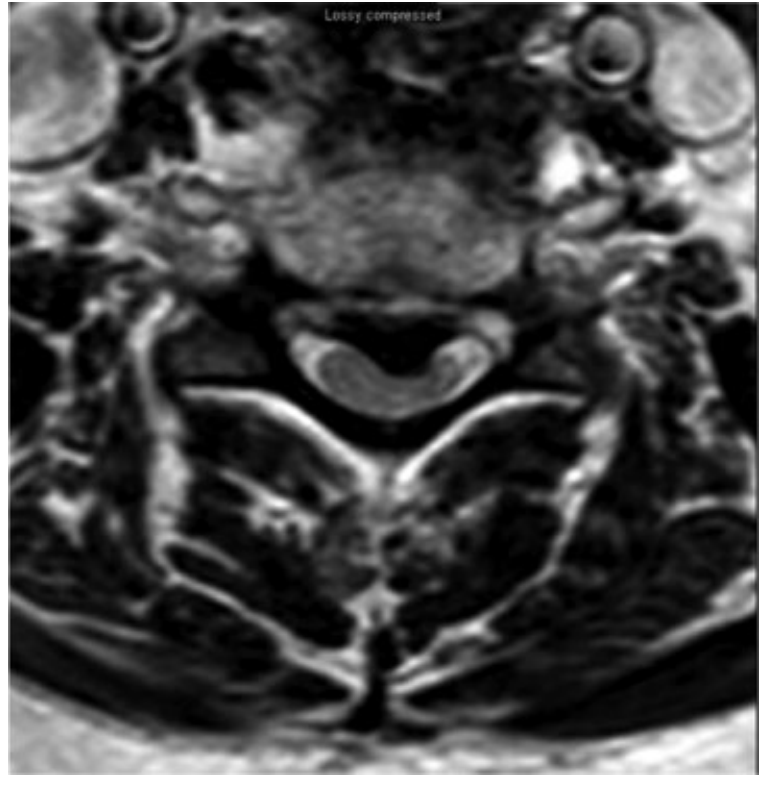

Fig. 3 T2 axial view of severe C4-5 stenosis.

and downgrading, and a more detailed evidence summary table are provided in the online supplementary material.

\section{Illustrative Case}

A 50-year-old woman presented with severe cervical myelopathy. She did have significant spondylosis diffusely along her spinal column, but only one site of cord compression (-Figs. 2 and 3). She underwent a single-level anterior cervical discectomy and fusion. Meticulous hemostasis was obtained and the wound was closed over a drain. On the evening of surgery, she became unresponsive and the emergency response team had difficulty establishing an airway. Fullness was noted at the incision site and the resident physician on call emergently opened the incision at the bedside and evacuated the suspected hematoma. The airway was secured and the patient was safely ventilated. The patient was returned to the operating theater where the surgical site was examined. No obvious source of bleeding was identified. The wound was irrigated and hemostasis was re-achieved and the wound was closed over a drain. The patient subsequently recovered without hypoxic or neurologic deficit.

\section{Discussion}

- The overall strength of evidence for the primary outcomes is insufficient, meaning that we have very little confidence in the effect estimates, making it difficult to draw firm conclusions ( - Table 3 ).

- Patient characteristics (e.g., comorbidities, operative indications, severity of condition) were generally different between the inpatient and outpatient groups so selection bias and confounding bias are important limitations of studies available for this systematic review.

- There are five comparative studies that address safety of inpatient versus outpatient surgeries; however, four have small sample sizes and only a small number have overlapping outcomes (hematoma [one study], mortality [two studies], dysphagia [two studies], infection [two studies], and hospital readmission [three studies]). Small sample sizes may preclude detection of rare events and demonstration of statistical difference between groups.

- Further study is required to more clearly define the role of outpatient cervical spine surgery. In addition, acceptable thresholds for complication have yet to be defined for outpatient cervical spine surgery. Acceptable thresholds for a complication like dysphagia are not comparable to acceptable thresholds for complications such as airway compromise, hypoxia, and death. Finally, clear identification and quantification of risk factors for complication will be useful in determining which patients may potentially be candidates for outpatient cervical spine surgery.

\section{Acknowledgments}

We thank Ned Sherry, BS, for assistance with data abstraction and critical appraisal of included studies.

Analytic support for this work was provided by Spectrum Research, Inc. with funding from AOSpine.

\section{Disclosures}

Michael J. Lee, Consultant: Stryker Spine

Iain Kalfas, Consultant: Stryker Spine

Haley Holmer, none

Andrea Skelly, none

\section{References}

1 Wright JG, Swiontkowski MF, Heckman JD. Introducing levels of evidence to the journal. J Bone Joint Surg Am 2003;85-A(1):1-3

2 Methods Guide for Effectiveness and Comparative Effectiveness Reviews. AHRQ Publication No. 10(12)-EHC063-EF. Rockville, MD: Agency for Healthcare Research and Quality April 2012. Available at: www.effectivehealthcare.ahrq.gov

3 West S, King V, Carey TS, et al. Systems to Rate the Strength of Scientific Evidence. Evidence Report/Technology Assessment No. 47 (Prepared by the Research Triangle Institute-University of North Carolina Evidence-based Practice Center, Contract No. 290-97-0011). Rockville, MD: Agency for Healthcare Research and Quality; 2002

4 Atkins D, Best D, Briss PA, et al; GRADE Working Group. Grading quality of evidence and strength of recommendations. BMJ 2004; 328(7454): 1490

5 Liu JT, Briner RP, Friedman JA. Comparison of inpatient vs. outpatient anterior cervical discectomy and fusion: a retrospective case series. BMC Surg 2009;9:3

6 Silvers HR, Lewis PJ, Suddaby LS, Asch HL, Clabeaux DE, Blumenson LE. Day surgery for cervical microdiscectomy: is it safe and effective? J Spinal Disord 1996;9(4):287-293

7 Stieber JR, Brown K, Donald GD, Cohen JD. Anterior cervical decompression and fusion with plate fixation as an outpatient procedure. Spine J 2005;5(5):503-507

8 Trahan J, Abramova MV, Richter EO, Steck JC. Feasibility of anterior cervical discectomy and fusion as an outpatient procedure. World Neurosurg 2011;75(1):145-148, discussion 43-44

9 Walid MS, Robinson JS III, Robinson ER, Brannick BB, Ajjan M, Robinson JS Jr. Comparison of outpatient and inpatient spine surgery patients with regards to obesity, comorbidities and readmission for infection. J Clin Neurosci 2010;17(12):1497-1498 


\section{Editorial Perspective}

EBSJ and its reviewers felt that the authors provided a succinct review of the available literature evaluating feasibility and safety of outpatient cervical spine surgery. A systematic review of the literature was performed using recognized techniques. Unfortunately, high-quality literature comparing inpatient and outpatient cervical surgery is lacking and only five studies that met the inclusion criteria were included. Altogether, there were only 281 outpatients and 813 inpatients included for all of the studies. The incidence of major complication rates was extremely small. The two major concerns regarding outpatient surgery (death and readmission due to respiratory compromise) were addressed. Three studies reported data on patients who needed to be readmitted following surgery due to a complication. Only one patient treated in an outpatient setting needed readmission.

The authors appropriately noted the shortcomings of the literature on this topic. It was observed that there was very little confidence in the effect estimates, making it difficult to draw firm conclusions. It was also noted that the small sample sizes likely precluded detection of rare events and demonstration of statistical difference between groups.

This is an important topic. Increasing pressure to reduce the cost of medical care has increasingly pressured a wider range of procedures to be treated as outpatients. This limited study did not have any disasters that resulted from outpatient cervical spine surgery. Patient selection, and recognition of at-risk patients, remains an immediate challenge for practitioners interested in pursuing cervical spine surgery on an outpatient basis. Who is a suitable candidate, and what patient with what type of surgery is preferably treated as an inpatient? Obesity and neck size, sleep apnea, bleeding dyscrasias, location of surgery, and surgical invasiveness all might be factors worth considering. EBSJ recognizes that the subject of outpatient spine surgery clearly is an area that could benefit from additional investigation. 